\title{
Mechanical Properties of Ag-Doped Top-Seeded Melt-Grown YBCO Pellets
}

\author{
C. E. Foerster ${ }^{a *}$, E. Lima ${ }^{a}$, P. Rodrigues Jr. ${ }^{a}$, F. C. Serbena ${ }^{a}$, C. M. Lepienski ${ }^{b}$, M. P. Cantão ${ }^{c}$, \\ A. R. Jurelo ${ }^{a}$, and X. Obradors ${ }^{d}$ \\ ${ }^{a}$ Universidade Estadual de Ponta Grossa, Departamento de Física, Ponta Grossa, PR, CEP 84030-000, Brazil \\ ${ }^{b}$ Universidade Federal do Paraná, Departamento de Física, C.P. 19044, Curitiba, PR, CEP 81531-990, Brazil \\ ${ }^{c}$ LACTEC, C.P. 19.067, Centro Politécnico da UFPR, Curitiba, PR, CEP 81.531-990, Brazil \\ ${ }^{d}$ Institut de Ciência de Materials de Barcelona, CSIC Campus de la UAB, Bellaterra 08193, Spain
}

(Received on 25 June, 2008)

\begin{abstract}
In the present work we report the mechanical properties of $c a(b)$-planes of Ag-doped top-seeded melt-grown $\mathrm{YBaCuO}(\mathrm{YBCO})$ pellets at different concentrations. Hardness and elastic modulus were obtained by instrumented indentation and fracture toughness by conventional Vickers indentation. Hardness profiles for both planes indicated values between 7-8 GPa at deep tip penetration. Significant differences in elastic modulus were observed as a function of $\mathrm{Ag}$ content for the $a b$-plane while no difference were seen for the $c a(b)$-plane. Doping with 5 wt. $\% \mathrm{Ag}_{2} \mathrm{O}$ increases the hardness and elastic modulus for the $a b$-plane in relation to the undoped sample due to Ag solid-solution hardening. Indentation fracture toughness rises with Ag doping for the $a b$-plane. Intensive plastic deformation was observed in $c a(b)$ plane for conventional Vickers indentation.
\end{abstract}

Keywords: YBaCuO; Anisotropy; Hardness; Elastic modulus; Instrumented indentation; Fracture toughness

\section{INTRODUCTION}

Despite its very fascinating applications in transport processes like supporting high critical current density and trapping of high magnetic fields at low nitrogen temperature, high- $T_{C}$ superconductors must have good mechanical and tribological performance for actual technological applications. Therefore, the study of mechanical properties of these compounds, such as of the hardness $(\mathrm{H})$, elastic modulus $(\mathrm{E})$ and fracture toughness $\left(\mathrm{K}_{I C}\right)$, is very crucial $[1,2]$.

Melt processed high- $T_{C}$ compounds have its mechanical properties affected by the melting procedure that creates defects like pores, cracks and oxygen vacancies [3]. In order to decrease these defect densities and to improve the mechanical properties, it is indicated to dope the high- $T_{C}$ matrix with $\mathrm{Ag}$ without loosing the transport properties [2-4]. The doped AgYBCO structure has Ag inclusions in addition to the Y211 grains in the Y123 matrix. These inclusions are formed if the Ag content surpasses the Ag solubility limit in the YBCO structure $[3,4]$.

Bulk hardness of YBCO determinated at room temperature has been mostly obtained by conventional Vickers measurements and the values are in the range from 5 to $8 \mathrm{GPa}[5,6]$. Elastic modulus values measured in the range from nitrogen to room temperature and having a broad interval between 100$160 \mathrm{GPa}[7]$.

In the present work different $\mathrm{Ag}_{2} \mathrm{O}$ contents $(0 \%, 5 \%, 10 \%$ and 15 wt. \%) were introduced in the precursors oxides in order to form textured Ag-doped YBCO pellets. Subsequently, the hardness and elastic modulus were measured by instrumented indentation on $a b$ and $c a(b)$-planes. The fracture toughness $K_{C}$ was also calculated in $a b$-plane by conventional Vickers indentations.

*E-mail address: carlosef@uepg.br

\section{EXPERIMENTAL PROCEDURE}

Single domain melt-textured YBCO pellets have been prepared by the top seeding technique using melt-textured $\mathrm{NdBa}_{2} \mathrm{Cu}_{3} \mathrm{O}_{7-\delta}$ seeds [3, 4]. Commercial powders of $\mathrm{YBa}_{2} \mathrm{Cu}_{3} \mathrm{O}_{7-x}, \mathrm{Y}_{2} \mathrm{BaCuO}_{5}, \mathrm{CeO}_{2}$ and $\mathrm{Ag}_{2} \mathrm{O}$ with purity of $99.9 \%$ were the precursors. The samples composition were 70 wt. $\% \mathrm{YBa}_{2} \mathrm{Cu}_{3} \mathrm{O}_{7-x}+30$ wt. $\% \mathrm{Y}_{2} \mathrm{BaCuO}_{5}$ doped with 1 wt. $\% \mathrm{CeO}_{2}$ and 5,10 or 15 wt. $\%$ of $\mathrm{Ag}_{2} \mathrm{O}$. The electrical characterization of these samples (not here shown) was performed with low-frequency-low-current $\mathrm{AC}$ technique that employed a lock-in amplifier as a null detector. For all of the Ag doped YBCO samples an onset resistivity transition temperature around $92 \mathrm{~K}$ was observed.

Room temperature hardness and elastic modulus profiles were determined by instrumented indentation following the Oliver and Pharr method [8]. The diamond tip was a Berkovich type and the applied loads ranged from 2.5 to 320 $\mathrm{mN}$. At these applied loads, near surface and bulk regions could be analyzed. The values here reported are the average at each tip depth obtained from a matrix indentations $(5 \times 5)$ at different regions on the $a b$ and $c a(b)$ planes. This procedure was used to check surface homogeneity in respect to the seed position. The fracture toughness was obtained by $0.5 \mathrm{~N}$ Vickers indentations and using the relation according to Anstins et al. [9]:

$$
K_{c}=\alpha\left(\frac{E}{H_{v}}\right)^{\frac{1}{2}} \cdot \frac{P}{c^{\frac{3}{2}}}
$$

where $\alpha$ is a geometrical constant equals to $0.016 \pm 0.004, c$ is the radial crack length and $P$ is the applied load. Impressions morphology was observed by scanning electron microscopy (SEM). 


\section{RESULTS AND DISCUSSION}

Typical Berkovich indentations for pure YBCO in $a b$ and $c a(b)$ planes are shown in Figs. $1 \mathrm{a}$ and $1 \mathrm{~b}$, respectively. Cracks nucleated by the indentations are observed around the tip impressions on the $a b$-plane (Fig. 1a). Moreover, there is a tendency of the cracks direction to follow the indenter diagonals or/and along specific crystallographic planes. These crystallographic orientations are reported in the literature as $\{100\}$ planes [10]. For the $c a(b)$-plane (Fig. 1b), no cracks were nucleated around the impressions.
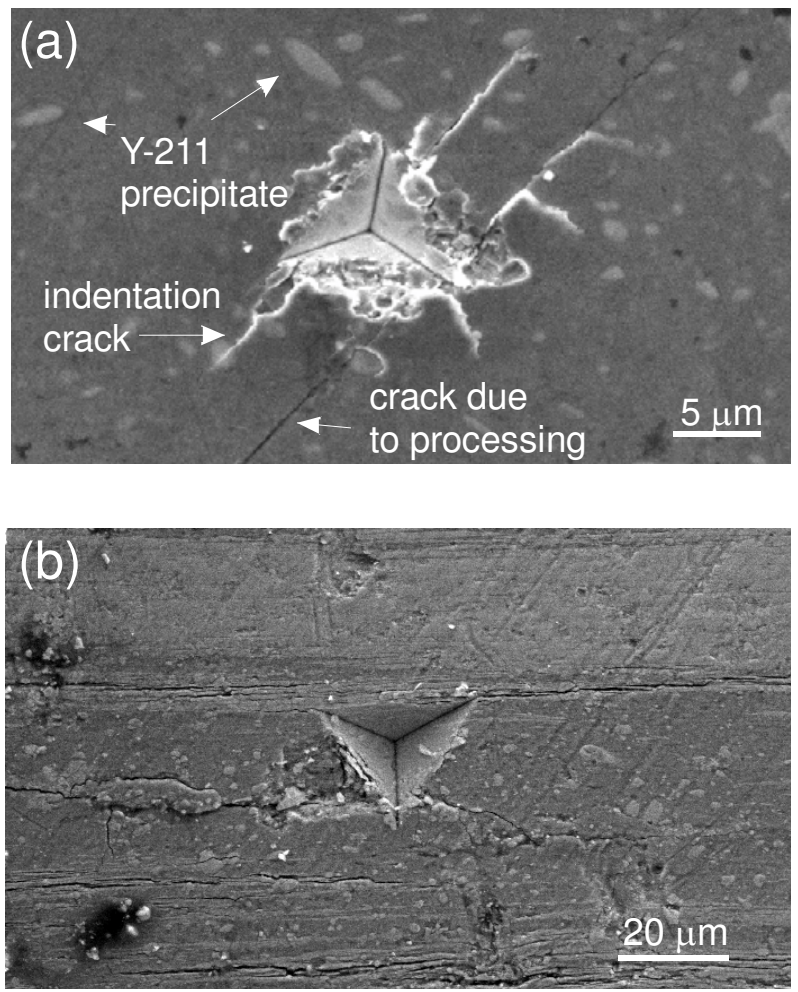

FIG. 1: SEM micrographs of $320 \mathrm{mN}$ Berkovich indentations for (a) $a b$-plane and (b) $c a(b)$-plane of pure YBCO

The Figs. $2 \mathrm{a}$ and $2 \mathrm{~b}$ show typical Vickers indentations performed on $a b$ and $c a(b)$-planes of YBCO with 15 wt. $\% \mathrm{Ag}_{2} \mathrm{O}$ in, respectively. In agreement to the observed in pure YBCO, cracks are nucleated in the $a b$-plane but not in the $c a(b)$-plane. However, in the $c a(b)$-plane it is now observed that the indented material is crushed and displaced around the impression as has been observed in lamellar materials [11]. In the present case, the use of indenters of different geometry is not responsible for the difference in the observed cracking behavior between the planes. Vickers indentations were performed on $a b$ and $c a(b)$-planes of pure YBCO and cracks were only observed in the $a b$-planes. Moreover, the Berkovich indenter has the same depth-to-area relation in respect to the Vickers indenter and consequently an equivalent behavior in relation to crack nucleation would be expected.

Figures $3 \mathrm{a}$ and $3 \mathrm{~b}$ show typical load/unloading curves at the maximum applied load for pure YBCO and for different $\mathrm{Ag}$
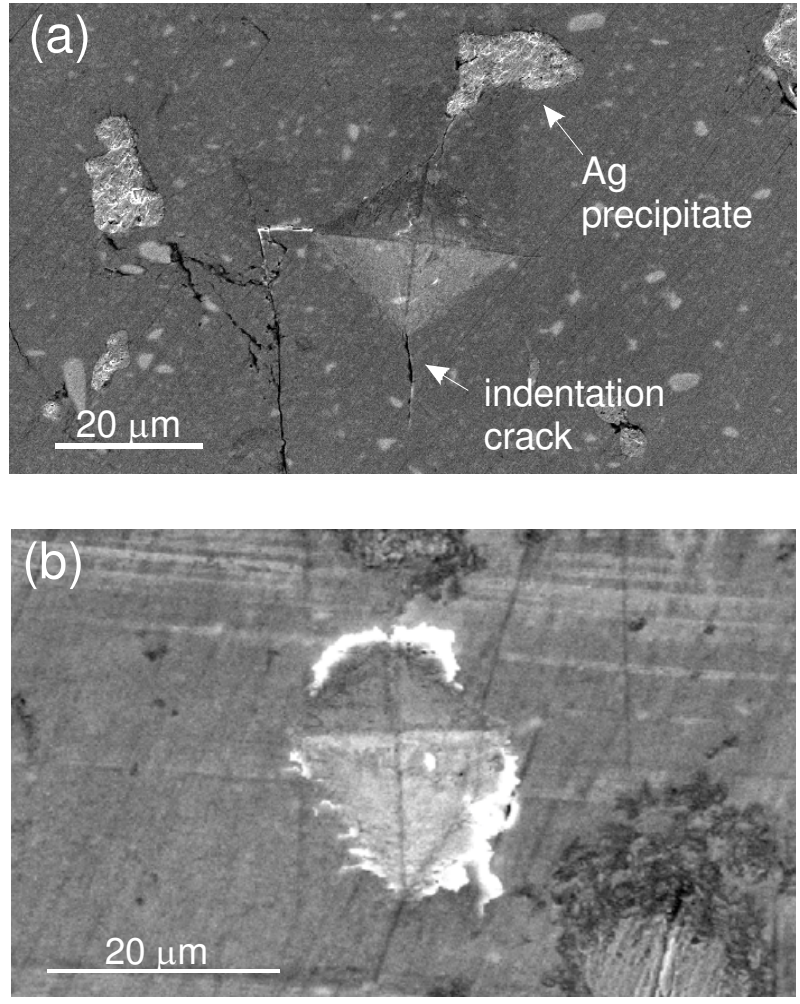

FIG. 2: SEM micrographs of $1 \mathrm{~N}$ Vickers indentations for (a) $a b$ plane and (b) $c a(b)$-plane of $\mathrm{YBCO}$ with 15 wt. $\% \mathrm{Ag}_{2} \mathrm{O}$.

concentration in $a b$ and $c a(b)$-planes, respectively. The shallowest tip penetrations for both planes were those with $5 \mathrm{wt}$. $\% \mathrm{Ag}_{2} \mathrm{O}$ concentration. Meanwhile, the penetrations depth of samples with 10 and 15 wt. $\% \mathrm{Ag}_{2} \mathrm{O}$ were higher than that for pure YBCO samples. Another point is that for both planes no tip incursions (pop-ins) were observed in the loading curves for the applied load. This means that no chipping occurred as a result of lateral crack detachment during the indentation tests [12].

Hardness profiles obtained by instrumented indentation are shown in Fig. 4 for both planes. Independent of the indented plane, the hardness profiles have a tendency to reach a constant value with deeper tip penetrations. Fig. 4a shows hardness profiles for $a b$-plane as a function of the tip penetration for pure YBCO and Ag-doped samples. It can be observed that at shallower depths (up to $400 \mathrm{~nm}$ ), the hardness is slightly higher than at deeper regions. This can be attributed to the indentation size effect and/or to the presence of defects or thin films at near surface region. The presence of defects can be those produced during polishing and, the films are due to the existence of insulating hydroxides and/or thin carbonate films formed as result of atmospheric exposure [13]. At deeper regions $(\sim 1300 \mathrm{~nm})$, the hardness is around $9 \mathrm{GPa}$ for low Ag content and $7 \mathrm{GPa}$ for the highest one, while for pure YBCO the value is $8 \mathrm{GPa}$. These differences among the hardness at different $\mathrm{Ag}$ contents can be attributed to a solid-solution hardening. This mechanism is possible because $\mathrm{Ag}$ atoms can be present within 

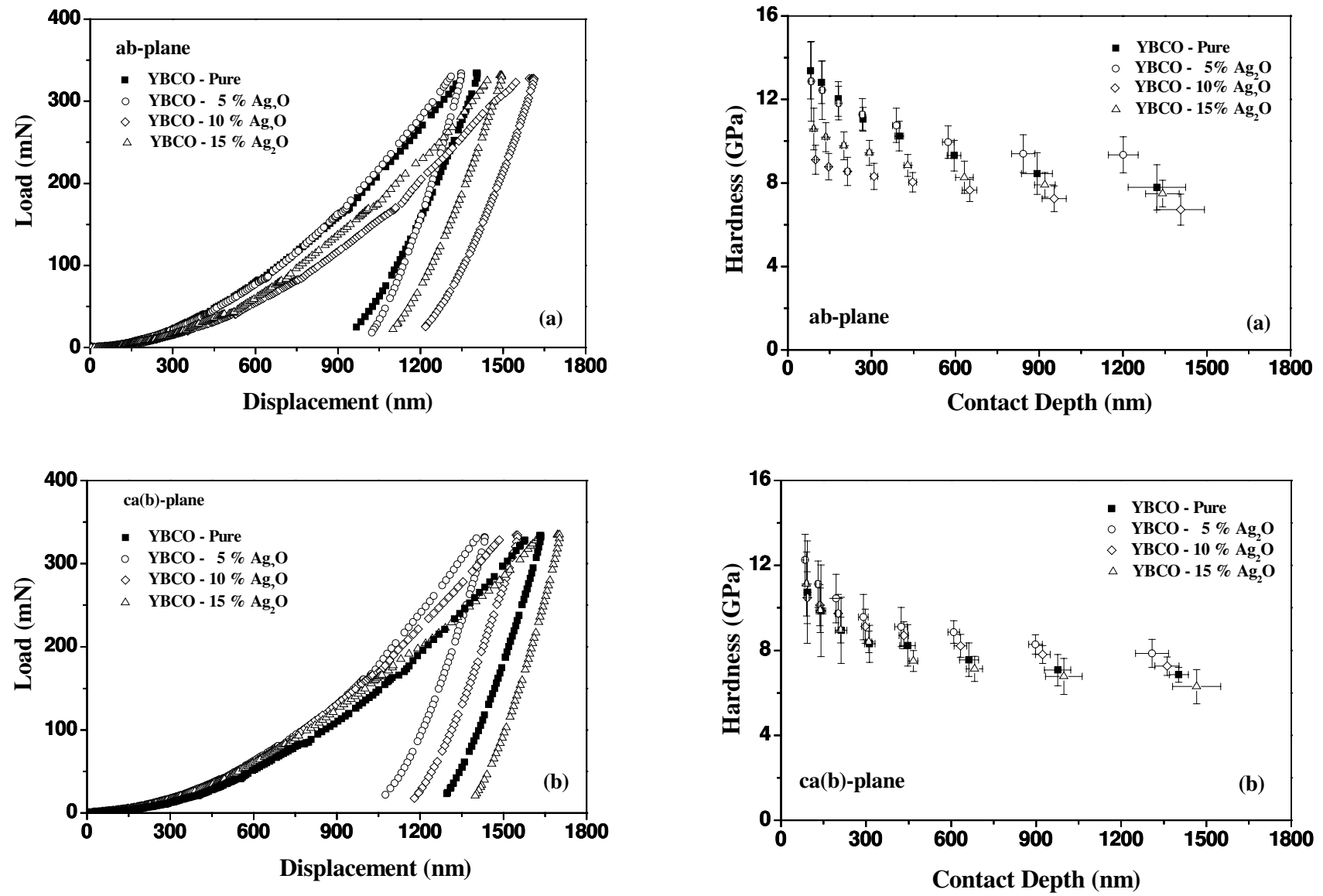

FIG. 3: Typical load-unloading curves for different Ag-doped pellets: (a) $a b$-plane and (b) $c a(b)$-plane.

the $\mathrm{YBa}_{2} \mathrm{Cu}_{3} \mathrm{O}_{7}$ grains, possibly in a substitutional type creating a $\mathrm{YBa}_{2}(\mathrm{Cu}, \mathrm{Ag})_{3} \mathrm{O}_{x}$ stoichiometry [14]. The $\mathrm{Ag}$ atoms change the dimensions of the unit cell, because the $\mathrm{Ag}$ ion size is larger than that of the $\mathrm{Cu}$ ion. It is also reported that $\mathrm{Ag}$ atoms saturates at nominal concentrations higher than 2.5 wt.\% Ag [14]. According to the literature [15], substitutional ions interact elastically with dislocations and consequently a higher stress is necessary for dislocation movement. In the case of $\mathrm{Ag}_{2} \mathrm{O} 5$ wt.\% doping, we expect this interaction yet to promote the maximum hardening. Increasing further the Ag concentration causes Ag precipitation in the bulk that will decrease the hardness.

Hardness profiles for $c a(b)$-plane at different $\mathrm{Ag}$ contents are shown in figure $4 \mathrm{~b}$. Despite a slightly higher hardness near the surface, the hardness dispersion is now lower than for $a b$-plane. However, hardness of about $6 \mathrm{GPa}$ and $8 \mathrm{GPa}$ were found for the highest and lowest Ag content, respectively. The hardness of $a b$-plane of the undoped YBCO is around $8 \mathrm{GPa}$ while for $a c(b)$-plane is $7 \mathrm{GPa}$. $\mathrm{Ag}_{2} \mathrm{O}$ addition initially increases the hardness but at high $\mathrm{Ag}_{2} \mathrm{O}$ content, the hardness decreases as similarly is observed in the $a b$-plane.

Figure 5a shows the elastic modulus profiles as a function of contact depth for the $a b$-plane. The pure YBCO sample has an elastic modulus of $180 \mathrm{GPa}$ at the deepest penetra-

FIG. 4: Profiles of hardness as a function of contact depth for different $\mathrm{Ag}_{2} \mathrm{O}$ concentrations: (a) $a b$-plane and (b) $c a(b)$-plane.

tion and this value agrees with literature data [16]. The 5 wt.\% $\mathrm{Ag}_{2} \mathrm{O}$ sample has the highest value (220 GPa), while increasing the $\mathrm{Ag}$ content further decreases the elastic modulus to $140 \mathrm{GPa}$. Fig. 5b shows the elastic modulus profiles for the $c a(b)$-plane. The hardness and elastic modulus obtained in the present work are similar for $a b$ and $c a(b)$-planes in comparison to pure YBCO. However, $\mathrm{Ag}$ addition at $5 \mathrm{wt}$. $\% \mathrm{Ag}_{2} \mathrm{O}$ during the melting process improves these values in both planes. Particularly, this increase is higher for $a b$-plane than for $a c(b)$-plane.

The mechanical properties measured and then employed to calculate the indentation fracture toughness for the $a b$-plane according to equation (1) are shown in table I. The Ag addition decreases the Vickers hardness, elastic modulus and crack lengths. The fracture toughness increases from 1.43 $\mathrm{MPa} \cdot \mathrm{m}^{1 / 2}$ for pure $\mathrm{YBCO}$ to $1.6 \mathrm{MPa} \cdot \mathrm{m}^{1 / 2}$ for $10 \mathrm{wt}$. \% $\mathrm{Ag}_{2} \mathrm{O}$ doped $\mathrm{YBCO}$. The fracture toughness obtained in this work is in agreement with values reported in the literature [16-18] for pure YBCO. Yeh and White [18] measured the fracture toughness using SENB (Single Edge Notch Bend) samples. From their work, $K_{I C}$ increased from $1 \mathrm{MPa}^{1 / 2}$ for undoped condition to $2.3 \mathrm{MPa} \cdot \mathrm{m}^{1 / 2}$ for $30 \mathrm{wt}$. $\% \mathrm{Ag}_{2} \mathrm{O}$. The extrapolated toughness for $10 \mathrm{wt}$. $\% \mathrm{Ag}_{2} \mathrm{O}$ concentration from their work yields a value of $1.6 \mathrm{MPa} \cdot \mathrm{m}^{1 / 2}$, which 
TABLE I: Microscopic mechanical properties: Vickers hardness $\left(\mathrm{H}_{V}\right)$, elastic modulus $(\mathrm{E})$, crack length $(\mathrm{c})$ and indentation fracture toughness $\left(\mathrm{K}_{C}\right)$ measured on the $a b$-plane.

\begin{tabular}{|l|l|l|l|l|}
\hline Sample $\left(\% \mathrm{Ag}_{2} \mathrm{O}\right)$ & $\mathrm{H}_{V}(\mathrm{GPa})$ & $\mathrm{E}(\mathrm{GPa})$ & $\mathrm{c}(\mu \mathrm{m})$ & $\mathrm{K}_{C}\left(\mathrm{MPa} \mathrm{m}^{1 / 2}\right)$ \\
\hline 0 & $5.2 \pm 0.2$ & $177 \pm 10$ & $47.5 \pm 0.4$ & $1.43 \pm 0.02$ \\
\hline 10 & $4.1 \pm 0.4$ & $149 \pm 4$ & $43.5 \pm 0.2$ & $1.6 \pm 0.1$ \\
\hline
\end{tabular}
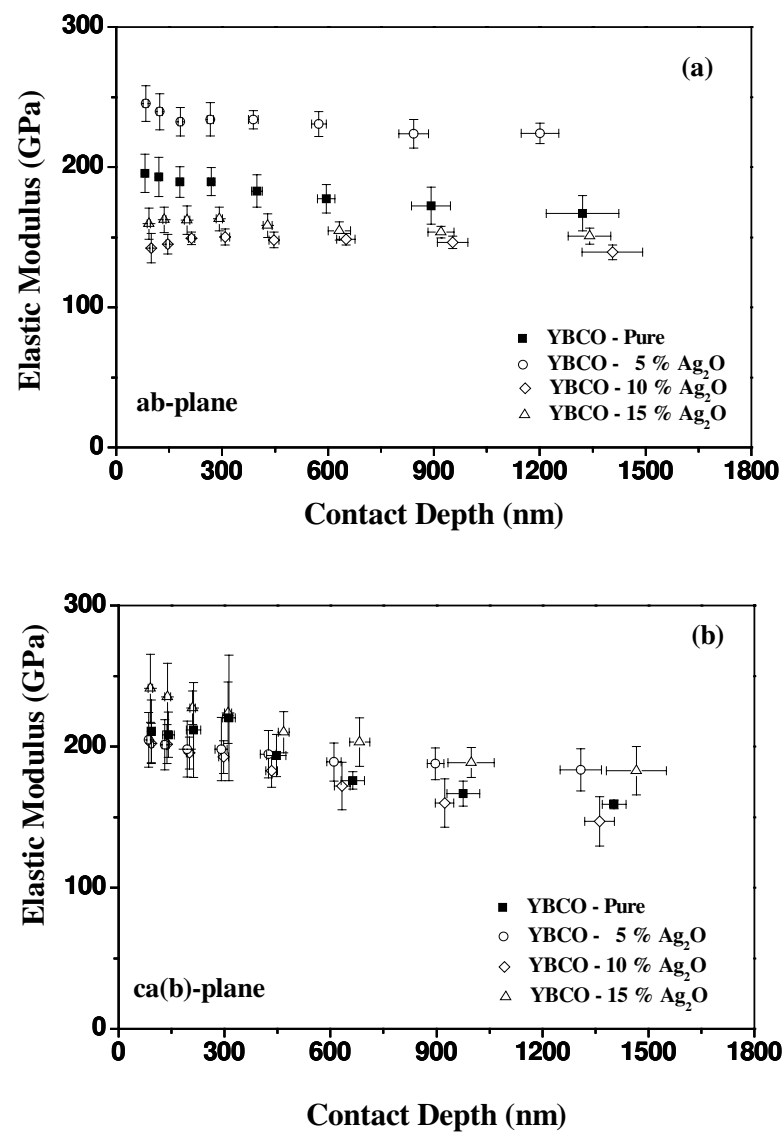

FIG. 5: Profiles of elastic modulus as a function of contact depth for different $\mathrm{Ag}_{2} \mathrm{O}$ concentrations: (a) $a b$-plane and (b) $c a(b)$-plane.

is in agreement with the value obtained in this study by nanomicroindentation methods.

It is known that the addition of $\mathrm{Ag}$ causes a reduction in the number of pores and cracks in the YBCO microstructure [16]. Also, the increase of its concentration produces higher tensile and bending strengths [10]. Miyamoto et al. [19] observed in melt-textured samples that Ag doping improves the mechanical properties of YBCO and SBCO using a strain gage technique as well as Markov et al. [20] noticed an increase of microplasticity of polycrystalline YBCO ceramic with 3-5 wt. $\% \mathrm{Ag}_{2} \mathrm{O}$ addition. Tancret et al. [16] observed in melttextured YBCO Ag-doped with Y-211 phase that an addition of $\mathrm{Ag}$ results in a reduction in more than $50 \%$ in porosity. These authors also reported an increase in grain size, a threefold increase in elastic modulus, a four-fold increase in fracture toughness and also an approximately five-fold increase in Vickers hardness. Roa et al. [21] measured similar values of hardness and elastic modulus, as here reported, by using the same instrumented indentation technique for the $a b$-plane of melt-textured YBCO.

Comparing the different literature data in respect to the mechanical properties of YBCO and Ag doped YBCO, it is observed a wide spread in the values of hardness, elastic modulus and fracture toughness. This can be attributed to the different processing routes employed to produce these materials.

\section{CONCLUSIONS}

Hardness, elastic modulus and indentation fracture toughness of Ag-doped top-seeded melt-grown YBCO pellets were measured by using indentation technique at room temperature. The maximum bulk hardness and elastic modulus were reached for a concentration of $5 \mathrm{wt} . \% \mathrm{Ag}_{2} \mathrm{O}$ for $a b$ - and $c a(b)$ planes. The hardness of the $a b$-plane was $\sim 9 \mathrm{GPa}$ for $5 \mathrm{wt} . \%$ $\mathrm{Ag}_{2} \mathrm{O}$ concentration while for pure $\mathrm{YBCO}$ was around $8 \mathrm{GPa}$. For higher $\mathrm{Ag}$ concentrations, the hardness decreased to 7 $\mathrm{GPa}$. The same behavior was observed for the $c a(b)$-plane, but with smaller hardness values. The differences can be attributed to a solid-solution hardening because the Ag atoms substitute the $\mathrm{Cu}(1)$ in the $\mathrm{YBa}_{2} \mathrm{Cu}_{3} \mathrm{O}_{7}$ matrix. The elastic modulus was also maximum for the $5 \mathrm{wt} . \% \mathrm{Ag}_{2} \mathrm{O}$ concentration reaching a value of $220 \mathrm{GPa}$ in respect to $180 \mathrm{GPa}$ or undoped condition. The doping with $\mathrm{Ag}$ increased the indentation fracture toughness from $1.43 \mathrm{MPa} . \mathrm{m}^{1 / 2}$ for pure $\mathrm{YBCO}$ to $1.6 \mathrm{MPa}^{1 / 2}$ with 10 wt. $\% \mathrm{Ag}_{2} \mathrm{O}$ concentration.

\section{Acknowledgements}

This work was partially financed by Conselho Nacional de Pesquisa (CNPq) under contract $n^{\circ}$ 474.077/2007-1.
[1] M. Murakami, in Melt Processed High Temperature Superconductors, edited by M. Murakami (World Scientific, Singapore, 1992) p. 21 .

[2] S. V. Lubenets, V. D. Natsik, and L. S. Fomenko, Low-Temp.
Phys. 30, 345 (2004).

[3] E. Mendoza, T. Puig, E. Varesi, A. E. Carrillo, J. Plain, and X. Obradors, Physica C 334, 7 (2000).

[4] X. Obradors, R. Yu, F. Sandiumenge, B. Martínez, N. Vilalta, 
V. Gomis, T. Puig, and S. Pinol, Supercond. Sci. Technol. 10, 884 (1997).

[5] Y. Yoshino, A. Iwabuchi, K. Noto, N. Sakai, and M. Murakami, Physica C 357-360, 796 (2001).

[6] S. V. Lubenets, V. D. Natsik, L. S. Fomenko, H. J. Kaufmann, V. S. Bobrov, and A. N. Isotov, Low-Temp. Phys. 23, 678 (1997).

[7] R. R. Reddy, M. Murakami, S. Tanaka, and P. V. Reddy, Physica C 257, 137 (1996).

[8] W. C. Oliver, G. M. Pharr, J. Mater. Res. 7, 1564 (1992).

[9] G. R. Anstis, P. Chantikul, B. R. Lawn, and D. B. Marshall, J. Am. Ceram. Soc., 64, 533 (1981).

[10] N. Sakai, S. J. Seo, K. Inoue, T. Miyamoto, and M. Murakami, Physica C 335, 107 (2000).

[11] A. Murugaiah, Nanoindentations in Kinking Nonlinear Elastic Solids, D. Phil thesis, University of Drexel, 2004.

[12] D. H. Mosca, N. Mattoso, C. M. Lepienski, W. Veiga, I. Mazzaro, V. H. Etgens, and M. Eddrief, J. Appl. Phys. 91, 140 (2002).

[13] R. P. Vasquez, B. D. Hunt, and M. C. Foote, Appl. Phys. Lett.
53, 2692 (1988).

[14] Ch. Zhang, A. Kulpa, and A. C. D. Chaklader, Physica C 252, 67 (1995).

[15] M. A. Meyers, K. K. Chawla, Mechanical Behavior of Materials (Prentice-Hall International, London, 1998, p. 464).

[16] F. Tancret, I. Monot, and F. Osterstock, Mater. Sci. Eng. A 298, 268 (2001)

[17] C. Lebiond-Harnois, R. Caillard, I. Monot-Laffez, G. Desgardin, and B. Raveau, Physica C 341-348, 2439 (2000).

[18] F. Yeh, K. W. White, J. Appl. Phys. 70, 4989 (1991).

[19] T. Miyamoto, K. Nagashima, N. Sakai, and M. Murakami, Physica C 340, 41 (2000).

[20] L. K. Markov, T. S. Orlova, N. N. Peschanskaya, B. I. Smirnov, Y. P. Stepanov, and V. V. Shpeizman, Phys. Solid State, 45, 1629 (2003).

[21] J. J. Roa, X. G. Capdevila, M. Martínez, F. Espiell, and M, Segarra, Nanotechnology 18, 385701 (2007). 